\title{
Kronieken voor een nieuwe tijd: Le Roseau d'or als cultureel brandpunt van een katholiek netwerk
}

MATHIJS SANDERS

Begin juni 1923 verruilde de filosoof Jacques Maritain zijn woonplaats Versailles voor het Parijse voorstadje Meudon, waar hij een woning had gekocht van het geld dat een in juni 1918 gesneuvelde bewonderaar, de infanteriekorporaal Pierre Villard, hem had nagelaten. ${ }^{1}$ In zijn kielzog volgden denkers, schrijvers en kunstenaars en aldus werd Meudon in de jaren twintig en dertig van de twintigste eeuw een centrum van intellectuele en artistieke bedrijvigheid. $\mathrm{Zij}$ die Maritain naar Meudon volgden voelden zich aangetrokken tot het programma dat hij in de jaren na de eerste wereldoorlog ontvouwde, dat van een 'renouveau catholique': een herstelbeweging die de moderne cultuur wilde bezielen met de eeuwenoude katholieke filosofie van de scholasticus Thomas van Aquino. Maritain voegde zich in zijn denken naar het neothomisme, een beweging binnen de katholieke kerk die met de pauselijke encycliek Aeterni patris van Leo xIII uit 1878 op gang was gekomen met als doel de katholieke geloofsleer van een stevig wijsgerig fundament te voorzien, waarmee deze de moderne tijd zou kunnen doorstaan. ${ }^{2}$ De beweging die Maritain vanuit Meudon op gang bracht, en die wel is gekarakteriseerd als een 'révolution à rebours', zou niet alleen de westerse cultuur van een wisse ondergang moeten redden, maar beoogde ook de eigentijdse literatuur te vernieuwen via een eeuwenoude traditie. ${ }^{3}$ Om deze niet geringe ambitie te verwezenlijken had Maritain een netwerk nodig van sympathisanten die het streven naar vernieuwing tegen de keer van 'la pensée moderne' in geschriften - en bij voorkeur in een eigen tijdschrift - kracht bij zouden zetten.

De netwerken die zich rond Maritain formeerden en de tijdschriftplannen die daaruit zijn voortgekomen hebben in de Franse literatuurgeschiedenis weinig aandacht gekregen. In de literair-historische handboeken gaat de belangstelling vooral uit naar auteurs, teksten en tijdschriften die kunnen 
worden geplaatst in een van de stromingen van de historische avant-garde (vooral het surrealisme) en in het modernisme (Proust, Valéry, de kringen rond Gide en het tijdschrift La Nouvelle Revue Française). De concentratie op deze heden ten dage canonieke lijnen heeft het zicht enigszins ontnomen op Maritains antimoderne herstelbeweging, een beweging waaraan internationale aspiraties ten grondslag lagen en ten aanzien waarvan velen hun positie meenden te moeten bepalen. ${ }^{4}$ Bestudering van de institutionele infrastructuur van de beweging levert een meer genuanceerd beeld op van het literaire en culturele verleden waarin deze beweging geworteld was en laat de complexiteit en dynamiek van de Franse literatuur in deze periode scherper uitkomen dan een benadering die Maritains beweging uitsluitend beschrijft in termen van individuele invloedsrelaties en verwantschap. ${ }^{5}$ In het navolgende zullen de zich uitbreidende internationale netwerken rond Maritain en de serie-uitgave Le Roseau d'or die uit deze netwerken geboren werd, beschreven worden. Bijzondere aandacht besteed ik aan het tijdschrift dat in de genoemde serie-uitgave besloten lag, de Chroniques. Tussen 1925 en 1930 verschenen negen afleveringen van dit tijdschrift als onderdelen van de reeks Ie Roseau d' or. Het was gedurende vijf jaar een brandpunt van literaire actualiteit. Hoewel de Chroniques nooit de uitstraling en kwaliteit hadden van tijdgenoten als de NRF of Commerce vormt het blad een verrassende verzamelplaats van zeer uiteenlopende auteurs uit verschillende Europese landen, zoals blijkt uit de hierna afgedrukte index.

De kiemcel van het internationale netwerk dat zich in de jaten twintig rond Maritain formeerde, lag in een informele discussiegroep die zich in 1914 had gevormd en die vanaf 1919 bekend stond als de 'Cercle d'Études Thomistes'. Grote inspirator van het gezelschap was de katholieke pamflettist Léon Bloy (1846-1917), onder wiens invloed Maritain zich in 1906 had bekeerd. Bloy slingerde zijn banvloeken naar de burgerlijke samenleving en naar katholieken die zich aan die samenleving conformeerden. Zelf had hij radicale consequenties verbonden aan zijn antimoderne cultuurkritiek. Hij propageerde een integraal katholicisme dat zijn beslag moest krijgen in een theocentrische maatschappij. De revolutie van 1789, die volgens hem de onttroning van God had ingeluid, moest worden gekeerd. Minder absolutistisch dan Bloy, maar bezield door eenzelfde ideaal, werkte Maritain, geïnspireerd door de filosofie van Thomas van Aquino, een programma uit dat het 


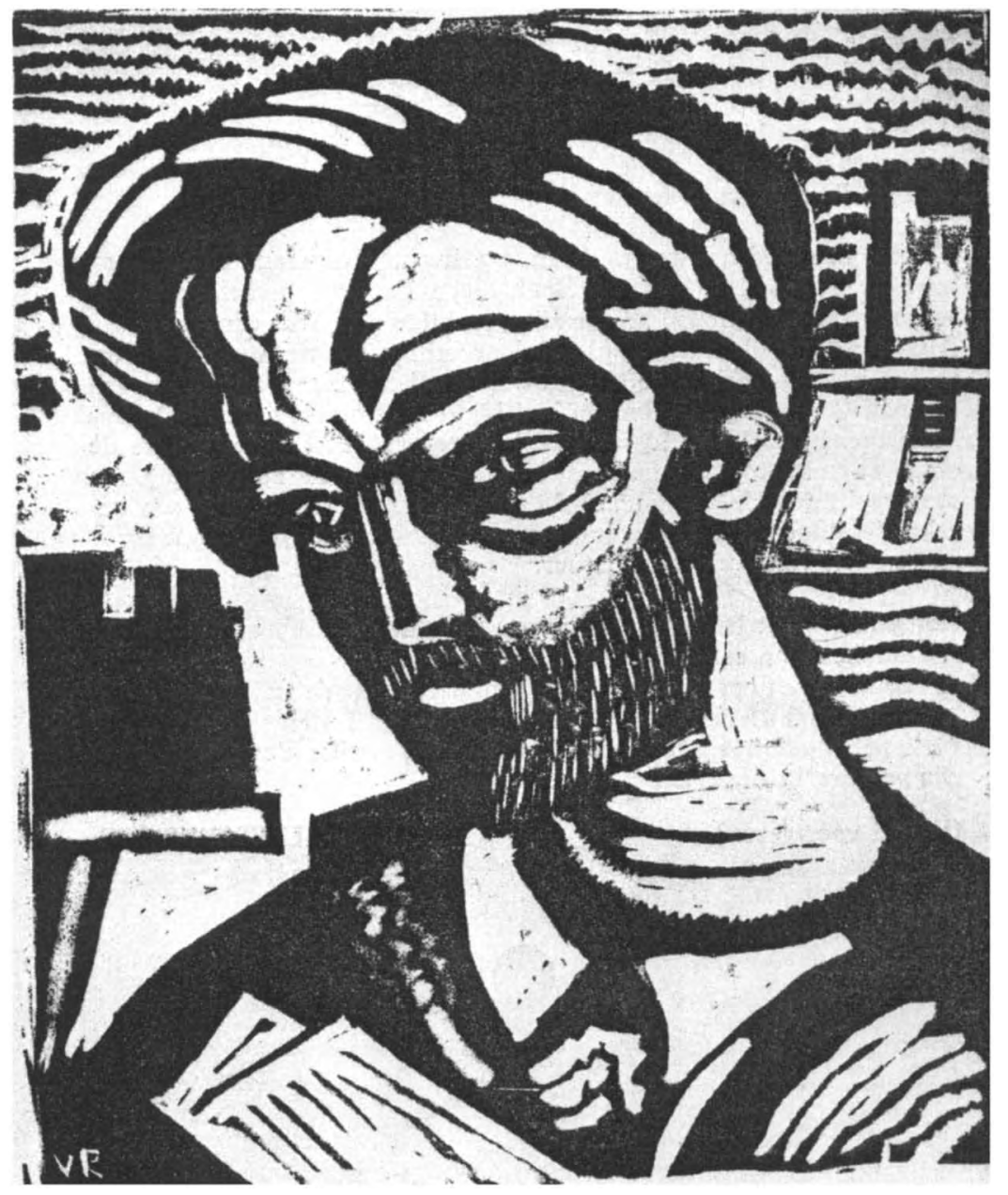

Portret van Jacques Maritain door Otto van Rees (houtsnede).

In: De Gemeenschap, jaargang 1, 1925. 
fundament moest vormen van een renouveau catholique. Dat programma was naar aard en intentie antimodern. Het greep over verlichting, renaissance en reformatie heen immers terug op de middeleeuwse scholastiek. Maar Maritain presenteerde zijn programma en de beweging die daaruit moest voortkomen voortvarend als ultramodern en Thomas van Aquino als 'apostel van de moderne tijd'. ${ }^{6}$ In het voorwoord van zijn programmatische essaybundel Antimoderne schreef hij:

Si nous sommes antimodernes, ce n'est pas par goût personnel, certes, c'est parce que le moderne issu de la Révolution antichrétienne nous y oblige par son esprit, parce qu'il fait lui-même de l'opposition au patrimoine humain sa spécification propre, hait et méprise le passé, et s'adore, et parce que nous haïssons et méprisons cette haine et ce mépris, et cette impureté spirituelle; mais s'il s'agit de sauver et d'assimiler toutes les richesses d'être accumulées dans les temps modernes, et d'aimer l'effort de ceux qui cherchent, et de désirer les renouvellements, alors nous ne souhaitons tant que d'être ultramodernes.?

Terwijl hij Luther, Descartes, Rousseau en Kant in de beklaagdenbank zette, poetste Maritain de middeleeuwse magister op en plaatste hem als boegbeeld op een beweging die het herstel van de westerse cultuut moest bewerkstelligen zonder de eigen tijd radicaal de rug toe te keren. ${ }^{8}$ In zijn filosofische en cultuurkritische exposé's plaatste Maritain alle menselijke faculteiten en scheppingen (de ratio, de wetenschap, de kunst) onder het primaat van het geloof. In zijn beroemdste boek, de kunsttheoretische verhandeling Art et scolastique (1920), beredeneerde hij op gezag van Thomas van Aquino het principe van de relatieve artistieke autonomie: kunst en literatuur waren vrij in hun eigen domein (dat niet het domein van zedelijkheid en moraal was), maar in laatste instantie waren zij ondergeschikt aan het hogere. Zo kon Maritain zich naar twee kanten afzetten: tegenover de voorstanders van een autonome esthetica poneerde hij de uiteindelijke ondergeschiktheid van kunst aan hogere principes, en tegenover critici die de kunst op de biechtstoel van de moraal zetten verdedigde hij de belangeloosheid van kunstwerk en kunstenaar. Met de nadruk die hij legde op het métier van 
de kunstenaar als ambachtsman, het aftasten van de traditie als bron voor vernieuwing en zijn pleidooi voor orde, vormbeheersing en discipline sloot Maritain in Art et scolastique aan bij de classicistische tendens die in de jaren twintig onder moderne kunstenaars als Cocteau, Stravinsky, Eliot en anderen terrein won. Voor deze tendens had Henri Ghéon in 1904 het begrippenpaar 'classicisme moderne' gemunt: vernieuwing kon in deze optiek uitsluitend totstandkomen via de weg van de traditie. ${ }^{9}$

Dankzij de erfenis van Villard was Maritain vanaf 1919 financieel onafhankelijk. Zijn aanstelling als 'professeur d'histoire de la philosophie moderne' aan het Institut Catholique te Parijs hield hij aan, maar het zwaartepunt van zijn activiteiten lag nu bij het schrijven en bij de 'zondagmiddagen' die hij samen met zijn echtgenote Raïssa en zuster Vera organiseerde in hun woning aan de Rue du Parc in Meudon. Tijdens deze informele middagen discussieerde Maritain met gelijkgestemde geesten over uiteenlopende, maar in hun optiek onlosmakelijk met elkaar verknoopte onderwerpen als de toekomst van Frankrijk, het katholicisme in de moderne tijd en de mogelijkheden van een door 'la vie spirituelle des saints' bezielde literatuur. De bijeenkomsten zullen bij menig deelnemer herinneringen hebben gewekt aan de fameuze 'dinsdagavonden' van de dichter Mallarmé aan de Parijse Rue de Rome, waaruit enkele decennia eerder de symbolistische dichtersbeweging was voortgekomen. Het huis en zijn bewoners werkten als een magneet op tijdgenoten die zich om uiteenlopende redenen voelden aangetrokken tot Maritains filosofie en esthetica, zonder dat zij allen de radicaliteit van de door Bloy geïnspireerde cultuurkritiek deelden. Als gevolg van zijn boeken La philosophie bergsonienne (1913), Art et scolastique (1920), zijn essays in La revue des jeunes (vanaf 1915) en La revue universelle (vanaf 1920) en dankzij zijn gezaghebbende positie aan het Institut Catholique verwierf Maritain binnen enkele jaren een centrale positie in het Franse intellectuele leven. De kringen die zich in Meudon om hem heen formeerden, bestonden uit een bonte verzameling filosofen, schrijvers, schilders en musici. Onder hen bevonden zich veel bekeerlingen. ${ }^{10}$ In zijn boek Entre Maurras et Maritain. Une génération intellectuelle catholique noemt Philippe Chenaux een groot aantal personen die de woning van Maritain en café Le Rotonde aan de Boulevard Montparnasse op Montmartre, dat als hoofdstedelijke uitwijkplaats fungeerde, frequenteerden: de componisten Igor Stravinsky en Arthur Lourié, de toneelschrijver 
en essayist Henri Ghéon, de schilder Georges Rouault en talrijke schrijvers onder wie Ernest Psichari, Maurice Sachs, Gino Severini, Julien Green, Jean Cocteau, Pierre Reverdy, Max Jacob, Stanislas Fumet, Henri Massis, Frédérique Lefevre, Georges Bernanos en de Nederlander Pieter van der Meer de Walcheren. ${ }^{11}$

Uit de bovenstaande opsomming blijkt dat Maritain niet enkel aantrekkingskracht uitoefende op geloofsgenoten. Ook niet-katholieke generatiegenoten die in hun zoektocht naar een bezield verband na de dood van God door een geestelijk reveil werden aangetrokken, richtten hun blik en voetstappen naar Maritain. Jean Cocteau en Max Jacob hadden furore gemaakt in de Parijse avant-garde, Jacob als dichter en Cocteau als veelzijdig kunstenaar en als de onvermoeibare impresario van de avant-gardistische scene. Beide kunstenaars zochten na de oorlog van 1914-1918 echter naar nieuwe bindingen. In hun zoektocht naar metafysische zingeving stonden zij in deze jaren bepaald niet alleen. Maritain was er veel aan gelegen deze kopstukken van de avant-garde aan zijn netwerk te verbinden, waardoor de beweging pas echt een moderne, vitale uitstraling zou krijgen en waardoor zijn positie tegenover andere kringen en tijdschriften als de NRF zou worden versterkt.

Om de buitenwereld duidelijk te maken waar Jacob en Cocteau werkelijk stonden spoorde Maritain Henri Massis aan om in een herdenkingsartikel over Raymond Radiguet de beide kunstenaars uit te spelen tegen de NRF, dat zich in deze jaren als het leidende tijdschrift profileerde: 'le moment est venu, me semble-t-il, d'accueillir tout ce mouvement [Cocteau en zijn vrienden, Ms] et de ne pas le laisser capter par la NRF, qu'il contrairie en réalité,' aldus Maritain in een brief aan Massis. ${ }^{12}$ Cocteau was overtuigd. Met zijn toetreding tot de kring van Meudon had hij zich in de ogen van veel vroegere bondgenoten onherstelbaar gecompromitteerd, maar Maritain kon tevreden zijn: 'En 1925, grâce à Cocteau et à sa bande, la petite maison des Maritains à Meudon était devenue l'un des lieux "à la mode" de la vie intellectuelle parisienne.' ${ }^{13}$ In een openbare briefwisseling brachten Cocteau en Maritain de uitgangspunten van Art et scolastique nog eens onder de aandacht van het publiek. ${ }^{14}$ Zoals uit het geciteerde brieffragment van Maritain blijkt was zijn strategie er mede op gericht de NRF en uitgeverij Gallimard - op dat moment al de meest prestigieuze literaire instituten van Frankrijk - te overtroeven. 


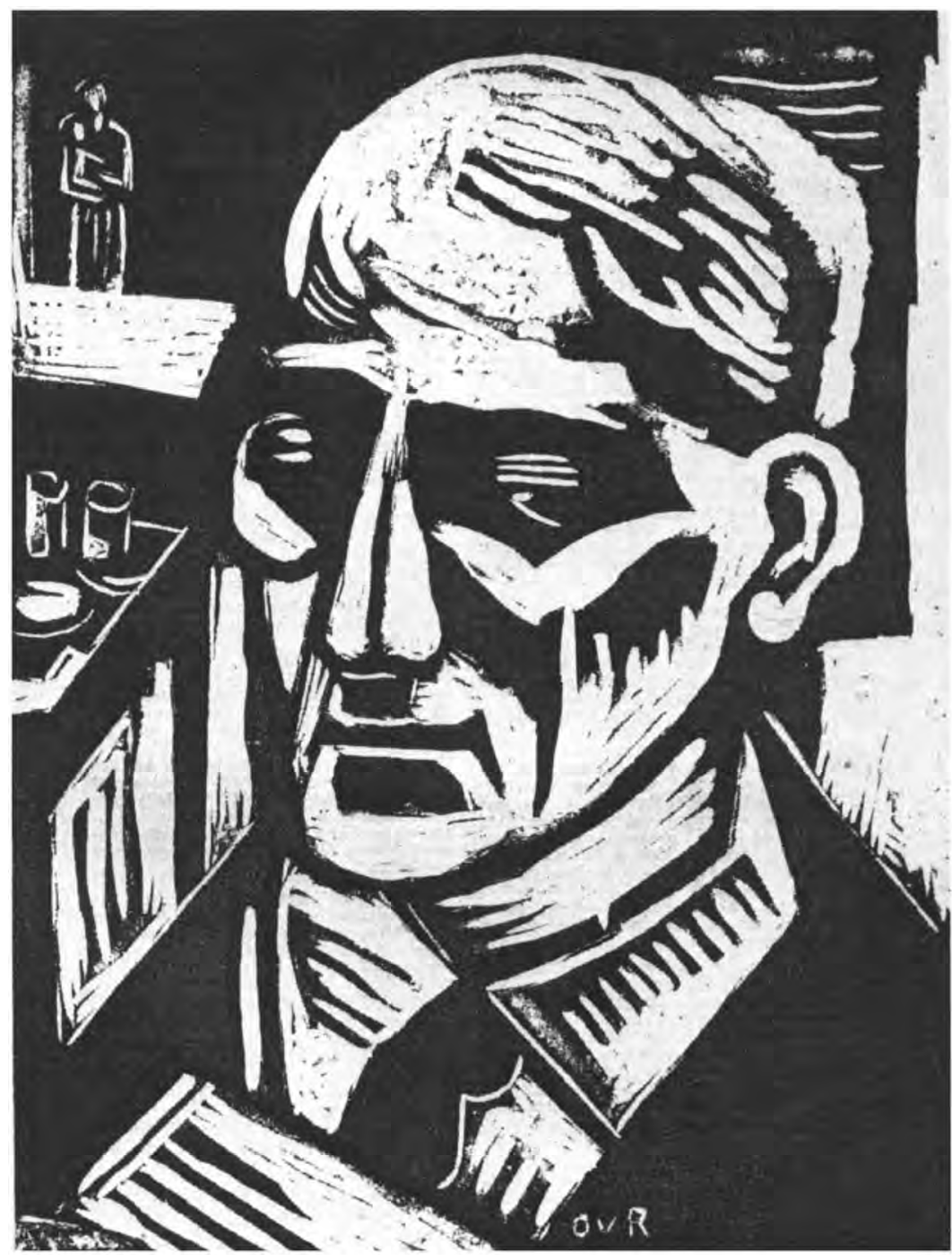

Portret van Max Jacob door Otto van Rees (houtsnede).

In: De Gemeenschap, jaargang 1, 1925. 
Minstens zo sensationeel als de entree van Cocteau was de toetreding van Henri Ghéon tot de formatie van Maritain. Ghéon was afkomstig uit de vriendengroep tond André Gide en was in 1908 een van de oprichters van de NRF. ${ }^{15}$ Zijn essaybundel Nos directions uit 1910 werd en wordt wel als het manifest van de NRF beschouwd. In de oorlog bekeerde hij zich tot het katholicisme. Van die bekering deed hij publiekelijk verslag in L'homme né de la Guerre. Témoignage d'un converti, dat in 1915 verscheen bij de 'Éditions de la Nouvelle Revue Française' (de voorloper van uitgeverij Gallimard). Toen de NRF in 1919 opnieuw begon te verschijnen keerde Ghéon zich tegen de groep van Gide en Rivière, waarop Maritain hem naar Meudon haalde. ${ }^{16}$

De bijeenkomsten in Meudon kregen al spoedig het aanzien van een 'salon littéraire'. Binnen dit door Maritain beheerde netwerk van vaste gasten en passanten ontstonden verschillende harde kernen vanwaaruit concrete initiatieven werden ontplooid. Vanaf mei 1921 organiseerde Maritain de 'Semaines des écrivains catholiques' en tussen 1922 en 1924 de 'Journées d'art religieux'. Tijdens deze bijeenkomsten konden katholieke schrijvers en kunstenaars elkaar ontmoeten en van elkaars werk en opvattingen kennisnemen. Van groot belang voor de institutionalisering van de beweging waren vooral de 'Retraites annuelles' die Maritain tussen 1922 en 1941 organiseerde en waarbij zich een internationaal gezelschap verzamelde in het cisterciënzerklooster te Meudon, 'une pléiade d'écrivains et d'artistes attirés par les choses de Dieu.'17 Chenaux doet de suggestie dat deze tiendaagse bijeenkomsten het katholieke equivalent moesten vormen van de fameuze 'Décades de Pontigny', waar de groep van Gide en de NRF vanaf 1910 nauw bij betrokken was en waarin internationale ambities gerealiseerd werden. ${ }^{18}$ Het aantal deelnemers aan de 'retraites' groeide van de kleine kring rond Maritain in 1922 tot zo' $n 150$ personen in $1931 .{ }^{19}$

Zoals uit de 'salon' in Meudon de 'Retraites annuelles' voortkwamen, zo vormden deze retraites op hun beurt in 1924 de voedingsbodem voor een publicitair initiatief: de oprichting van een serie-uitgave en een periodiek. Aanvankelijk gingen de gedachten uit naar een tijdschrift dat als tegenspeler kon optreden van de NRF van Rivière, 'une réplique à la NRF'. ${ }^{20}$ Tegenover het individualisme, elitarisme en autonome estheticisme (de afwijzing van engagement) van de 'néo-proustiens' wilden Maritain, Massis, Fumet en Lefevre een tijdschrift plaatsen dat gemeenschapsidealen uitdroeg en 
de urgentie zou tonen van een onlosmakelijke band tussen katholicisme en kunst. Dit idee werd eind 1924 heroverwogen. Maritain en Massis stelden een plan op voor een publicatiereeks waarin meer omvangrijke teksten - fictie en essayistiek - konden verschijnen en die kon gelden als 'une NRF catholique'. ${ }^{21}$ Er werd gezocht naar een uitgever die aan de reeks een uitstraling kon geven waarmee Gallimard geëvenaard of zelfs overtroffen kon worden. Uiteindelijk werd de Parijse uitgeverij Plon bereid gevonden de reeks - die Le Roseau d'or werd gedoopt, naar Apocalyps 21:15 - op de markt te brengen. Maritain, Fumet, Lefevre en Massis vormden de 'équipe de direction'. Bij de oprichting van de reeks waren ook Cocteau en Ghéon als toekomstige redacteurs nauw betrokken. ${ }^{22}$ Met de uitgeverij stelden zij de formule vast: de reeks zou het midden moeten houden tussen een tijdschrift en een serie, er zouden zowel monografieën als bundels in verschijnen met een frequentie van één uitgave per maand. De uitgaven zouden een omvang van 200 tot 450 pagina's hebben en zouden worden gedrukt in een oplage van 3300 tot 6600 exemplaren. Er werden jaarlijks tien uitgaven geprojecteerd in een serie waarop men voor 115 francs kon intekenen. De opzet voorzag verder in een constructie waardoor teksten konden worden uitgebracht van auteurs die nog onder contract stonden bij een andere uitgeverij (zoals Claudel, die een contract 'voor het leven' had getekend bij Gallimard). De reeks zou geen uitgesproken programma hebben en geen exclusief katholieke koers varen. Maritain moet zich hebben gerealiseerd dat een al te uitgesproken en exclusieve levensbeschouwelijke signatuur de reikwijdte van de onderneming ernstig zou beperken. Bovendien had hij in deze jaren afstand genomen van Bloy's radicalisme ten faveure van een houding die toenadering tot andersdenkenden impliceerde. ${ }^{23}$

Twee keer per jaar zou er in Le Roseau d'or een deel Chroniques uitkomen met uiteenlopende teksten van verschillende auteurs. Deze Chroniques leken nog het meest op een tijdschrift. De negen banden waren afzonderlijk genummerd ('Premier numéro de Chroniques', etc.) en gepagineerd. In een kleinere letterpunt op de kaft werd aangegeven dat de Chroniques deel uitmaakten van een groter geheel: de serie Le Roseau d'or. Een rubrieksindeling kenden de afleveringen niet. De Chroniques boden ruimte aan literaire teksten en aan essays over literaire, cultuurfilosofische, wijsgerige en religieuze onderwerpen. De 
opzet was dus algemeen-cultureel met een sterk accent op literatuur. Programmatisch waren de Chroniques weinig uitgesproken. De korte tekst waarmee de eerste aflevering, verschenen in december 1925, opende kan evenwel worden beschouwd als het manifest van Le Roseau d'or. Maritain schreef daar dat de reeks vooral geestelijke waarden uit zou dragen en de blik zou richten op de internationale artistieke actualiteit, maar dat het initiatief beslist niet als de manifestatie van een 'school' moest worden gezien: 'Le Roseau d'or, nous ne saurions trop y insister, ne sera donc l'organe ni d'une école littéraire, ni d'une génération littéraire.'24 Geestelijk gehalte, kwaliteit en authenticiteit van de bijdragen zouden volgens Maritain richtinggevend zijn voor het opnamebeleid. Programmatisch was wel de nadrukkelijk classicistische literatuur- en cultuuropvatting: de reeks zou bijdragen aan 'cette universelle réinvention de l'ordre véritable qui s'impose à notre temps'. 'Ordre' was hier voor de goede verstaander een signaalwoord dat duidde op een anti-romantische intentie: tegenover het individualisme en nationalisme van de romantiek poneerden Maritain en zijn geestverwanten een classicisme waarin gemeenschapszin en traditiebewustzijn samengingen. ${ }^{25}$ Chenaux stelt dat aan Le Roseau d'or eenzelfde streven ten grondslag lag als aan Art et scolastique: een brug slaan tussen de katholieke traditie en de moderne kunst. ${ }^{26}$

Tussen 1925 en 1932 verschenen onder de imprint Le Roseau d'or in totaal tweeënvijftig uitgaven, waaronder negen Chroniques. Als eerste deel van Le Roseau d'or verscheen in juni 1925 Maritains essaybundel Trois réformateurs: Luther, Descartes, Rousseau, gevolgd door het toneelstuk Le Comédien et la Grâce van Henri Ghéon. Op een medewerkerslijst uit 1932 prijken naast de namen van personen uit de kring rond Maritain (Lefêvre, Ramuz, Cocteau, Jacob, Fumet, Reverdy), ook die van Paul Claudel, Julien Green, Francis Jammes, Jacques Rivière, Valery Larbaud, Georges Bernanos (Sous le soleil de Satan, de eerste bestseller in het fonds) en van enkele gerenommeerde buitenlanders die in Frankrijk al enige bekendheid genoten omdat werk van hen in andere tijdschriften (N R F, Commerce, Le Navire d'Argent, Les Écrits Nouveaux) was verschenen: G.K. Chesterton, Johannes Jörgensen, Franz Hellens, Giovanni Papini, Giuseppe Ungaretti, Daisy Ashford, Rainer Maria Rilke en T.S. Eliot. ${ }^{27}$

Uit deze opsomming blijkt dat Maritain en de zijnen met Le Roseau d'or internationale aspiraties hadden. Aan de onderneming lag een kosmopoli- 
tische mentaliteit ten grondslag. Daarmee onderscheidde zij zich van de nationalistische en soms xenofobe tendensen binnen andere Franse katholieke cultuurbewegingen, die het sterkst tot uitdrukking kwamen in Charles Maurras' Action Française, een beweging waarvan Maritain zich vanaf 1927 (na de pauselijke veroordeling van Maurras' beweging) nadrukkelijk distantieerde. ${ }^{28}$ In dat opzicht voelden Maritain en de zijnen zich meer aangetrokken tot het kosmopolitisme van een tijdschrift als de NRF, zij het dat Maritain dat kosmopolitisme nadrukkelijk in religieuze banen wilde leiden en dat de Europese oriëntatie niet uitsloot dat hij Frankrijk beschouwde als de bakermat en het centrum van Europa. Door de programmatisch ruime opzet en het nadrukkelijke kosmopolitisme wist Maritain schrijvers aan de reeks te binden die ook hun diensten bewezen aan periodieken als de NRF en Commerce. Bestudering van de negen Chroniques brengt het kosmopolitisme van Le Roseau d'or aan het licht.

Een van de auteurs van buiten de kring van Maritain die aan de Chroniques bijdroeg en die men niet meteen zou verwachten in een katholiek gezelschap was Valery Larbaud, schrijver van A.O. Barnabooth: Ses ouvres complètes, c'est-à-dire un conte, ses poésies et son journal intime (1913), literair criticus, impresario van het internationale modernisme, bemiddelaar voor James Joyce en Italo Svevo in Frankrijk, verbonden aan de NRF en sinds de oprichting in 1924 redacteur van Commerce. ${ }^{29}$ In de vierde aflevering van Chroniques schreef hij een korte inleiding op werk van de Spaanse dichter Eugenio d'Ors, gevolgd door een tekst van deze auteur, vertaald door Larbaud en Mercédès Legrand. In de zesde aflevering volgde een toelichting bij de poëzie van de Argentijnse dichter Ricardo Guïrlandes, gevolgd door Larbauds vertaling van enkele mystieke gedichten van deze schrijver. ${ }^{30}$ Voor de Chroniques speelde Larbaud naar het zich laat aanzien een vergelijkbare rol als voor andere periodieken waaraan hij meewerkte: die van leverancier van buitenlandse teksten, die hij inleidde en vertaalde. ${ }^{31}$ Hoewel Larbaud met de groep van Le Roseau d'or een kosmopolitische oriëntatie, een uitgesproken voorkeur voor modern classicisme en een sterk ontwikkeld traditiebewustzijn deelde, ligt het voor de hand te veronderstellen dat zijn medewerking aan de Chroniques, zoals aan veel andere tijdschtiften, niet voortkwam uit affiniteit met de zaak van Maritain maar uit de wens in zoveel mogelijk tijdschriften te publiceren zonder zich aan een groep te binden. ${ }^{32}$ Op zijn beurt zal Maritain beseft hebben dat 
de aanwezigheid van deze gerenommeerde lettré in zijn tijdschrift het aanzien en prestige van de onderneming ten goede zou komen.

Kosmopolitisch toonde Maritain zich met de Chroniques ook in de opname, steeds in vertaling, van buitenlandse literatuur. Daarvoor maakte de redactie graag gebruik van bemiddelaars die teksten konden aanleveren en, indien nodig, inleiden en vertalen; een beproefde formule in deze periode, getuige het redactiebeleid van internationaal georiënteerde tijdschriften als de NRF en Commerce. ${ }^{33}$ Jean Cocteau, Jean de Menasce, Valery Larbaud en Jean Chuzeville hebben als leveranciers en vertalers voor de Chroniques gefungeerd, sommigen structureel (Cocteau), anderen meer incidenteel (Larbaud, Chuzeville en Eliotvertaler De Menasce). Te midden van het buitenlandse literatuuraanbod vetscheen, naast de genoemde teksten van de door Larbaud aangebrachte Spaanstalige auteurs, werk van Rainer Maria Rilke en Giuseppe Ungaretti (die beiden ook als bemiddelaar waren verbonden aan Commerce), van de Amerikaanse schrijfster Daisy Ashford (haar novelle The Young Visitors, aangebracht, ingeleid en vertaald door Cocteau), van de Russische dichter Alexei Rémizov en essayist Boris Zaïtzeff, van de Engelse essayist Francis Thompson, en van de Deense romancier Johannes Jörgensen. ${ }^{34}$

Het voert hier te ver om alle buitenlandlijnen in detail te belichten. De wegen waarlangs deze schrijvers de Chroniques binnenkwamen vergen nadere bestudering op basis van archiefonderzoek. Ik beperk mij hier tot één enkele casus.

T.S. Eliot had Maritain leren kennen tijdens zijn verblijf in Frankrijk in 1925, waar Eliot onder meer voorbereidingen trof voor de Clark Lectures die hij in februari en maart 1926 zou houden aan Cambridge University. Eliot verdiepte zich toen in het thomisme, waarin hij nieuwe waarden voor de Europese cultuur hoopte te vinden en een mogelijke uitweg uit zijn creatieve impasse. Eliots verlangen naar herstel van de culturele eenheid en zijn nostalgie naar een verleden waarin die eenheid intact zou zijn geweest, namen in deze jaren sterk religieuze vormen aan. 'A new form of Thomism offered at least the possibility of re-establishing the principles of order and lucidity, just as in his Cambridge lectures he wanted to demonstrate how that original unity had disintegrated,' schrijft Eliots biograaf Peter Ackroyd. ${ }^{35}$ Vanaf 1922 was Eliot al betrokken bij de NRF als correspondent voor 


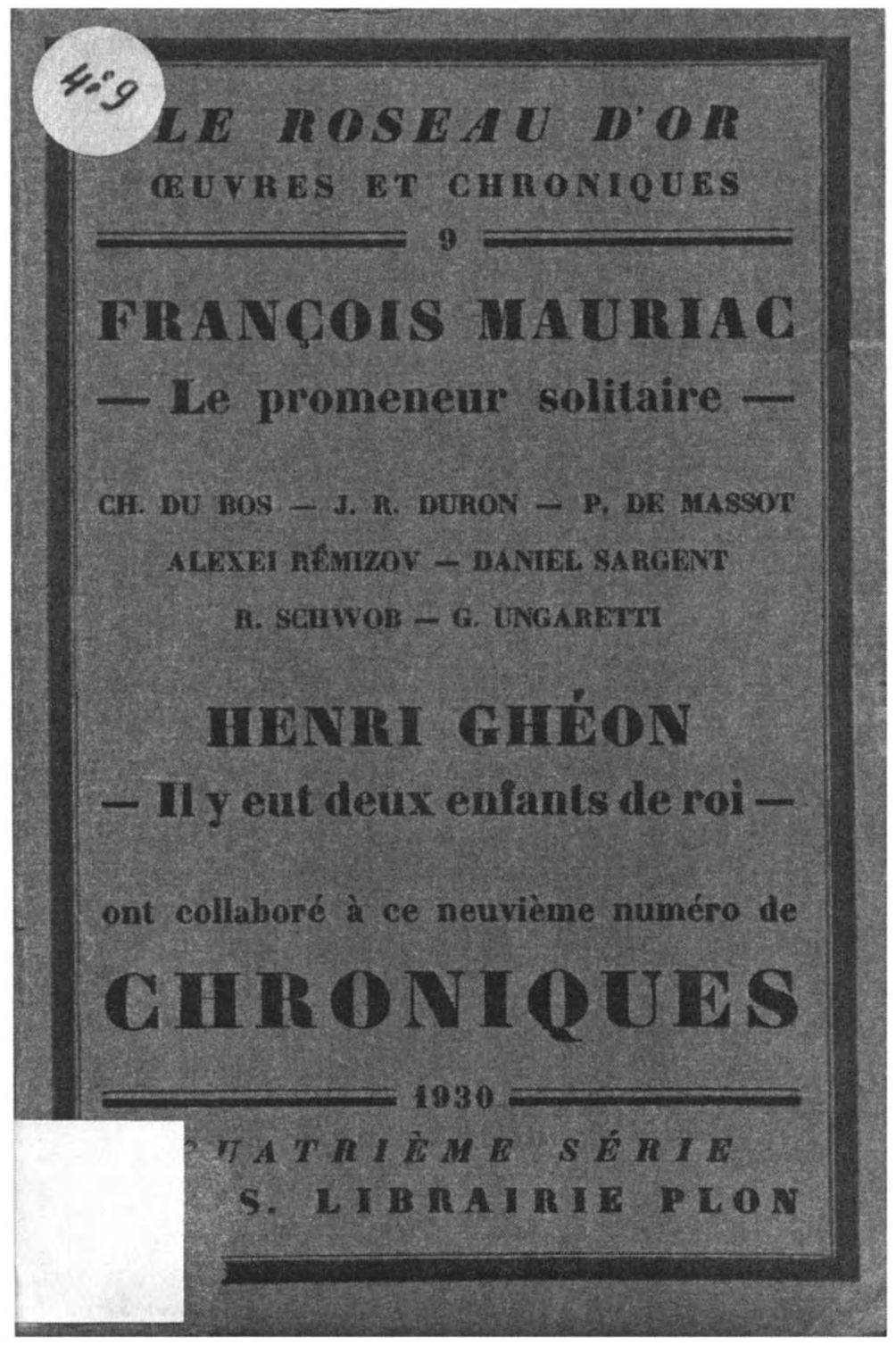

Omslag van Chroniques no. 9, 1930. 
de Engelse literatuur en in deze functie zou hij ook Commerce dienen. ${ }^{36}$ De betrokkenheid van Eliot bij de groep van Maritain resulteerde in twee bijdragen voor Le Roseau d'or. In de derde Chroniques (1927) verscheen 'Deux attitudes mystiques : Dante et Donne', de vertaling door Jean de Menasce van een van Eliots Clark Lectures, waaruit zijn classicistische opvatting van de traditie als klankbord voor vernieuwing spreekt. ${ }^{37}$ In de zevende editie van Chroniques (1929) volgde 'Cantique pour Siméon', de vertaling van 'A Song for Simeon' uit 1928, een van de Ariel Poems die verschenen kort na Eliots toetreding tot de Anglicaanse Kerk. Meer dan tussen Maritain en Larbaud was er tussen Eliot en Maritain sprake van wederzijdse verwantschap. Eliots verwantschap met Maritain resulteerde in de publicatie van Maritains essay 'Poetry and Religion', vertaald door de dichter F.S. Flint, in Eliots eigen tijdschrift The New Criterion van januari en mei $1927 .{ }^{38}$ Maritain recapituleert in dat essay de hoofdlijnen van Art et scolastique: hij benadrukt de relatieve autonomie van de kunst, keert zich tegen de romantische substitutie van religie door literatuur door auteurs als Mallarmé en Wilde en stelt dat kunst en religie samen het moderne materialisme moeten keren. Het standpunt van de relatieve autonomie had ook Eliot eerder verwoord, onder andere in zijn 'Notes' voor The Criterion van juli 1923, waarin hij het de voornaamste functie van het literaire tijdschrift noemde 'to maintain the autonomy, and the disinterestedness of literature, and at the same time to exhibit the relation of literature [...] to all the other activities'. ${ }^{39}$ In zijn beroemd geworden essay 'The Idea of a Literary Criticism' had Eliot met instemming gewezen op Maritains Réflexions sur l'Intelligence, waarvan hij de classicistische, antiromantische tendens waardeerde. ${ }^{40}$ Eliot en Maritain vonden elkaar in hun pleidooi voor een modern classicisme en kosmopolitisme zonder nauw omlijnd programma, in een gelijkgerichte cultuurkritiek en in hun ideaal van in de Europese traditie gewortelde religiositeit, kunst en literatuur.

De strategie van Maritain en van de équipe van le Roseau d'or bestond uit een gefaseerde vergroting van de actieradius van hun onderneming, die gaandeweg steeds meer internationale allure kreeg: van de huiselijke 'salon', via de 'semaines', 'journées' en 'retraites' naar de uitgavenreeks waarmee - gezien de oplagecijfers en de tijdspanne van vijf jaar waarin de Chroniques verschenen - een groot en internationaal publiek kon worden bereikt. ${ }^{41}$ Via de aantrekkelijk vormgegeven en inhoudelijk consistente reeks bij Plon, 
waar zowel gerenommeerde als beginnende auteurs publicatiemogelijkheden kregen, breidde het sociale en literaire netwerk rond Maritain zich verder uit als kringen in het water. De reeks trok spoedig de aandacht, zowel in Frankrijk als daarbuiten. Van een imprint werd Le Roseau d'or een merknaam: de aanduiding van een schrijversgeneratie. ${ }^{42}$

Uit de studie van Chenaux en uit het voorgaande is gebleken dat in de complexe Franse literaire constellatie van de jaren twintig drie sterrenstelsels om elkaar heen en soms in elkaar draaiden: de Parijse avant-garde (vooral het surrealisme), de modernisten rond de NRF en andere tijdschriften (Gide, Rivière, Paulhan, Larbaud, Valéry) en de kringen rond Maritain. De ontwikkeling binnen deze constellatie was er een van fusies en botsingen. In de NRF van juni 1925 laakte Ramon Fernandez het initiatief en de opvattingen van Maritain. ${ }^{43}$ Gezien het feit dat enkele prominente medewerkers van de NRF (onder wie Ghéon en buitenlandcorrespondent Eliot) naar Maritain waren 'overgelopen' en de redactie van Le Roseau d'or in 1925 een editie uitbracht van de correspondentic tussen Jacques Rivière en Paul Claudel met een inleiding van Isabelle Rivière waarin Rivière postuum naar de katholieke kring werd toegetrokken, moet de équipe van de NRF Le Roseau d'or en de Chroniques als een luis in de pels hebben beschouwd. ${ }^{44}$ Van een afstand beschouwd kunnen beide tijdschriften echter worden geplaatst in eenzelfde context: die van de internationalisering van het literaire bedrijf in het interbellum. Duidelijk is dat Le Roseau d'or en de Chroniques deels gemodelleerd waren naar de NRF, waar zij zich tegelijk tegen afzetten. Kwalitatief werd het niveau van de NRF en Commerce niet gehaald, maar dat maakt de onderneming als kristallisatiepunt van een internationale katholiek-classicistische tendens niet minder interessant.

In maart 1930 verscheen de laatste Chronique. Over de redenen voor het beëindigen van de reeks werden in de slotaflevering geen mededelingen gedaan. Het is aannemelijk dat de oprichting van een nieuw tijdschrift de belangrijkste oorzaak was voor de geruisloze opheffing. Zo vonden enkele redacteurs en vaste medewerkers van de Chroniques onderdak in het tijdschrift Vigile, dat vanaf 1930 een verzamelplaats was voor katholieke intellectuelen (vooral oude en nieuwe bekeerlingen). ${ }^{45}$ Ook dit tijdschrift paarde programmatische openheid aan internationale ambities, getuige de redactionele verantwoording in het eerste nummer. ${ }^{46}$ 
Deze eerste en voorlopige interpretatieve beschrijving van de negen Chroniques brengt aan het licht dat de literaire actualiteit aanmerkelijk gecompliceerder en minder gecompartimenteerd was dan de handboeken veelal doen uirkomen. Onderzoek naar cultuurbewegingen als de Renouveau Catholique kan aan precisie en reikwijdte winnen wanneer dat wordt uitgevoerd vanuit een institutionele benadering. Een overigens informatierijk boek als dat van Gugelot, La conversion des intellectuels au catholicisme en France, waarin de relaties tussen personen uit diverse katholieke kringen worden beschreven in termen van 'invloed' en 'verwantschap', maar waarin de instituties en de internationale netwerkvorming naar de achtergrond zijn geschoven, zou aan scherpte hebben gewonnen wanneer Le Roseau d'or en de Chroniques daarin waren geanalyseerd als plaatsen waar de herstelbeweging totstandkwam. ${ }^{47}$ Een tijdschrift als de Chroniques vormt een uitnodiging voor de literatuurgeschiedschrijver om een internationaal perspectief te hanteren dat verder reikt dan het inmiddels traditionele receptie-onderzoek en dat de institutionele verstrengeling van het literaire veld laat uitkomen via bestudering van tijdschriften, uitgevers en bemiddelaars. Auteurs, zo blijkt ook uit de hiervoor beschreven Eliot-casus, trekken zich vaak weinig aan van nationale grenzen, maar des te meer van bemiddelaars en internationale publicatiemogelijkheden. Juist het doorbreken van deze grenzen door publicaties van binnen- en buitenlandse auteurs uit diverse geledingen van het literaire veld gaven de Chroniques hun kleur. Een institutionele benadering van de literatuurgeschiedenis, die zich niet uitsluitend concentreert op vernieuwing maar evenzeer op continuïteit en traditie, zou erbij gebaat kunnen zijn wanneer het nationale kader wordt opgerekt ten faveure van de interpretatieve cartografie van het literaire veld en van de permanente dynamiek van fusies en botsingen, coöperaties en competities. Tijdschrift- en netwerkonderzoek kan hiertoe een belangrijke bijdrage leveren. ${ }^{48}$

> MATHIJS SANDERS is als docent en onderzoeker verbonden aan de opleidingen Algemene Cultuurwetenschappen en Literatuunwetenschap van de Radboud Universiteit Nijmegen en is sinds de oprichting redacteur van TS $>$. 


\section{Index op de Chroniques}

TOELICHTING

Hieronder volgt de chronologische index op de negen Chroniques van Le Roseau d'or. Euvres et chroniques. Deze is opgesteld aan de hand van de exemplaren die zich bevinden in de bibliotheek van de Radboud Universiteit Nijmegen onder signatuur Tzc3042. Het tekstgente wordt vermeld als:

$\operatorname{Pr}=$ verhalend proza

$\mathrm{Pz}=$ poëzie

Ess $=$ essay

$\mathrm{T}=$ toneel

$\mathrm{Br}=$ open brief

INDEX

Le Roseau d'or. CEuvres et chroniques

Librairie Plon. Plon-Nourrit et Cie, imprimeurs-éditeurs (aflevering 1-3)

Librairie Plon. Les petits-fils de Plon et Nourrit, imprimeurs-éditeurs (aflevering 4-9)

8 , rue Garancière, Paris, 6e

AFLEVERING 1 (LE ROSEAU D'OR, NR. 5), 1925

$\begin{array}{ll}\text { Genre } & \text { Auteur } \\ \text { Ess. } & \text { [Anoniem] } \\ \mathrm{T} & \text { Paul Claudel } \\ \mathrm{Pz} & \text { Jean Cocteau } \\ \text { Ess. } & \text { Jacques Maritain } \\ \mathrm{Pr} . & \text { C.-F. Ramuz } \\ \text { Ess. } & \text { Robert Honnert } \\ \mathrm{Pz} . & \text { Jean Cocteau } \\ \text { Ess. } & \text { Max Jacob } \\ \text { Ess. } & \text { Stanislas Fumet } \\ \mathrm{Pr} . & \text { Pierre Reverdy } \\ \text { Pz. } & \text { Jean Cocteau } \\ \text { Ess } & \text { Hilaire Belloc }\end{array}$

Titel

Le Roseau d'or

Le Soulier de satin - Première journée ${ }^{49}$

Le Feu du feu

Grandeur et misère de la métaphysique

Chant des pays du Rhône

Pagina

Le Désir et la joie

La Jeune fille qui dort

Pèlerinages, nage!

Une autre idée de l'ordre

Lueurs des braises du couchant ${ }^{50}$

Raymond Radiguet

La Conscience catholique de l'histoire ${ }^{51}$
I 
AFLEVERING 2 (LE ROSEAU D'OR, NR. 1O), 1926

\begin{tabular}{|c|c|c|c|}
\hline Genre & Auteur & Titel & agina \\
\hline Ess. & Humbert Clérissac & La Messagère de la Politiquedivine ${ }^{52}$ & \\
\hline \multirow[t]{2}{*}{$\mathrm{Pz}$} & Max Jacob & Renoncer à toute tichesse - Jeunesse lacustre & \\
\hline & & - Angoisses et autres & \\
\hline \multirow[t]{3}{*}{ Ess. } & Henri Massis & Charles Maurras et le sentiment de la mort. - & \\
\hline & & Paul Valéry et sa pensée. - Anatole France et le soldat. & \\
\hline & & Si Péguy était là. & \\
\hline Ess. & Nicolas Berdiaeff & Le Destin de la culture & \\
\hline $\mathrm{T}$. & Justin Klotz & Scènes dans le Paradis & \\
\hline Pr. & Jean Aurenche & Les Frères cachés & \\
\hline Ess. & Jean Cocteau & Daisy en France & \\
\hline Pt. & Daisy Ashford & Les Jeunes Visiteurs ou le Plan de Mr Salteena ${ }^{53}$ & \\
\hline Pz. & Alfredo Gangotena & Veillée ${ }^{54}$ & \\
\hline \multirow[t]{2}{*}{ Ess. } & Emile Dermenghem & Erasme et Thomas More contre Machiavel ou & \\
\hline & & la Politique et la Morale & \\
\hline Pr. & Julien Green & La Traversée inutile & 24 \\
\hline \multirow[t]{2}{*}{ Pr. } & Paul Sabon & I. Mariage ${ }^{55}$ & 26 \\
\hline & & II. Les Bisons Porteciel & \\
\hline Ess. & Léopold Levaux & La Chine et les Missions ${ }^{56}$ & 27 \\
\hline Ess. & Jules Lebreton & Les Traces de Dieu dans la vie de Jacques Rivièrc & 31 \\
\hline \multirow[t]{2}{*}{$\mathrm{Br}$. } & Georges Bernanos & Lettre à Frédéric Lefevre & 38 \\
\hline & AFLEVERING 3 (LE RC & U D'OR, NR. 14), 1927 & \\
\hline Genre & Auteur & Titel & Pagin \\
\hline Ess. & Jacques Maritain & Frontières de la Poésie 57 & \\
\hline $\mathrm{Pz}$ & Francis Jammes & Philomèle (traduit de saint Bonaventure) ${ }^{58}$ & 57 \\
\hline Ess. & Jacques Rivière & Russie ${ }^{59}$ & \\
\hline \multirow[t]{2}{*}{ Pz. } & Pierre Reverdy & Les Murs des villes. - Mille murmures dans le rang. - & \\
\hline & & Solitude. - Immense bruit. - Chemin tournant. - & \\
\hline Ess. & Robert Honnert & Les Lendemains de conversion ou l'équilibre difficile & \\
\hline \multirow[t]{2}{*}{ Pr./Pz. } & Jean Cocteau & Les Photographies de Bérénice. - Le Printemps. - & 14 \\
\hline & & Les Alliances. - & \\
\hline Ess. & T.S. Eliot & Deux attitudes mystiques: Dante et Donne $e^{60}$ & 14 \\
\hline Pz. & Max Jacob & Poème & \\
\hline
\end{tabular}

TS.> MMIV \# 16 


$\begin{array}{ll}\text { Ess. } & \text { Louis Guilloux } \\ \text { Pr. } & \text { Julien Lanoë } \\ \text { Pz. } & \text { Georges Hugnet } \\ \text { Ess. } & \text { Victor Poucel } \\ \text { Pz. } & \text { Jacques Reynaud } \\ \text { Pr./Ess. André Harlaire }\end{array}$

Sur l'offence

La Gitane charme les astres. - Mort, manoir

AFLEVERING 4 (LE ROSEAU D'OR, NR. 20), 1927

\begin{tabular}{|c|c|c|c|}
\hline Genre & Auteur & Titel & Pagina \\
\hline Ess. & Frédéric Lefevre & Une Nouvelle Psychologie du langage ${ }^{62}$ & I \\
\hline $\mathrm{Pz}$. & Alexei Rémizov & La Passion de la Vierge ${ }^{63}$ & 83 \\
\hline Ess. & Pierte Termier & La Vocation de Savant & 101 \\
\hline Ess. & Louis Massignon & $\begin{array}{l}\text { L'Expérience mystique et les modes de } \\
\text { stylisation littéraire }\end{array}$ & 141 \\
\hline Ess. & Stansislas Fumet & La Philosophie d'Ernest Hello & 177 \\
\hline Pr. & Pierre Humbourg & Mort de Capuri ${ }^{64}$ & 249 \\
\hline Ess. & Marcel Brion & Un Poète mystique : Angelus Silesius & 277 \\
\hline Ess. & Valery Larbaud & Eugenio d'Ots & 307 \\
\hline Pr. & Eugenio d'Ors & Trois natures mortes ${ }^{65}$ & 311 \\
\hline Ess. & André Harlaire & Visage d'une inquiétude & 315 \\
\hline \multirow[t]{2}{*}{ Ess. } & Emile Baumann & Mon Frère le Dominicain (son enfance et sa mort) & 335 \\
\hline & AFLEVERING 5 (LE & U D'OR, NR. 24), 1928 & \\
\hline Genre & Auteur & Titel & Pagina \\
\hline Ess. & Hilaire Belloc & M. Wells et Dieu ${ }^{66}$ & \\
\hline \multirow[t]{5}{*}{ Pz. } & Max Jacob & Poèmes & 65 \\
\hline & Paul Sabon & & \\
\hline & Georges Hugnet & & \\
\hline & Pierre Colle & & \\
\hline & Elie Gothchaux & & \\
\hline Pr. & André Beucler & Retard des trains ${ }^{67}$ & 85 \\
\hline \multirow[t]{2}{*}{ Br. } & Eugenio d'Ors & Lettre ouverte à M. Valery Larbaud sur la & 119 \\
\hline & & hiérarchie des esprits & \\
\hline Pr. & Robert Honnert & Je soigne ma fille & 125 \\
\hline Pr. & Maurice Beerblock & Somnol & 133 \\
\hline
\end{tabular}




\begin{tabular}{|c|c|c|c|}
\hline $\mathrm{Pz}$. & Mercédès de Gournay & Une jeunesse & 147 \\
\hline Ess. & Jean de Menasce & Situation du sionisme 68 & 153 \\
\hline & \multicolumn{3}{|c|}{ AFLEVERING 6 (LE ROSEAU D'OR, NR. 30), 1928} \\
\hline Genre & Auteur & Titel & Pagina \\
\hline Ess./Pz. & Emile Dermenghem & Visions et Poèmes de Marie des Vallées 69 & 1 \\
\hline Ess. & Jacques Maritain & Dialogues $^{70}$ & 17 \\
\hline Ess. & Valery Larbaud & Ricardo Güirlandes (1886_1927) & 63 \\
\hline Pz. & Ricardo Güirlandes & Poèmes mystiques ${ }^{71}$ & 67 \\
\hline Pr. & Marcel Arland & Le Retour ${ }^{72}$ & 73 \\
\hline Pr. & Pierre Reverdy & Les Graines de la liberté & 167 \\
\hline Pr. & Franz Hellens & Les Patins de cristal & 179 \\
\hline \multirow[t]{2}{*}{ Ess. } & Boris Zaïtzeff & Saint Serge de Radonège $e^{73}$ & 191 \\
\hline & \multicolumn{3}{|c|}{ AFLEVERING 7 (LE ROSEAU D'OR, NR. 3), 1929} \\
\hline Genre & Auteur & Titel & Pagina \\
\hline $\mathrm{T}$. & Paul Claudel & Conversations dans le Loir-et-Cher : «Jeudi » & 1 \\
\hline $\mathrm{Pz}$ & T.S. Eliot & Cantique pour Siméon 74 & 69 \\
\hline Ess. & Charles du Bos & Extraits d'un Journal75 & 73 \\
\hline Ess. & Francis Thompson & & 127 \\
\hline Ess. & R.M. & Le Prince de ce monde & 181 \\
\hline \multirow[t]{2}{*}{ Ess. } & Johannès Joergensen & Paysages goethéens & 197 \\
\hline & \multicolumn{3}{|c|}{ AFLEVERING 8 (LE ROSEAU D'OR, NR. 6), 1929} \\
\hline Genre & Auteur & Titel & Pagina \\
\hline Pz. & Rainer Maria Rilke & Deux poèmes du livre $d^{\prime} h e u r e s^{78}$ & 1 \\
\hline Ess. & Jacques Maritain & Bergonisme et métaphysique ${ }^{79}$ & 5 \\
\hline Ess. ${ }^{80}$ & Wladimir Ghika & Pensées pour la suite des jours & 133 \\
\hline Ess. & Henri Gouhier & $\begin{array}{l}\text { Les années d'apprentisage de Claude-Henri } \\
\text { de Saint-Simon }\end{array}$ & 139 \\
\hline Ess. ${ }^{81}$ & Judith Erèbe & A main armée & 207 \\
\hline Ess. & Etienne Borne & Propos sur Alain & 219 \\
\hline Ess. & Paul Sabon & Essai sur l'actualité & 279 \\
\hline Ess. & Peter Wust & La crise occidentale ${ }^{82}$ & 309 \\
\hline
\end{tabular}


AFLEVERING 9 (LE ROSEAU D'OR, NR. 9), 1930

$\begin{array}{lllr}\text { Genre } & \text { Auteut } & \text { Titel } & \text { Pagina } \\ \text { Pz. } & \text { Giuseppe Ungaretri } & \text { Caïn } & 1 \\ \text { Ess. } & \text { Francois Mauriac } & \text { Le Promeneur solitaire } & 5 \\ \text { Pz. } & \text { Pierre de Massot } & \text { L'Exécuteur testmentaire } & 29 \\ \text { Ess. } & \text { Charles du Bos } & \text { Sur «Marius l'Epicurien » de Walter Pater } & 39 \\ \text { Pr. } & \text { Alexei Rémizov } & \text { Pétouchok } & 83 \\ \text { Pz./Pr. } & \text { Daniel Sargent } & \text { Courtoisie } & 129 \\ & & \text { Le Jugement dernier } & \\ \text { Ess. } & \text { René Schwob } & \text { Chagall85 } & 130 \\ \text { Ess. } & \text { Jacques Robert Duron } & \text { Sagesse ou l'article de la mort } & 133 \\ \text { T. } & \text { Henri Ghéon } & \text { Il y eut deux enfants de roi } & 151 \\ & & & 205\end{array}$

1 Villards testament, gedateerd 6 mei 1918 , bepaalde dat zijn vermogen van twee miljoen francs zou worden verdeeld over twee erfgenamen van wie volgens hem de toekomst van Frankrijk afhing: Jacques Maritain en Charles Maurras, de leider van de Action Française. Over Maritain: B.W. Smith, Jacques Maritain. Antimodern or Ultramodern? An Historical Analysis of his Critics, his Thought, and his Life. New York [etc.] 1976; J. Dunaway, Jacques Maritain. Boston 1978; B. Doering, Jacques Maritain and the French Catholic Intellectuals. Notre Dame 1983; B. Hubert \& Y. Floucat (eds.), Jacques Maritain et ses contemporains. Parijs 1991; Jude P. Doughtery, Jacques Maritain. An Intellectual Profile. Washington 2003.

2 Zie G.A. McCool, Catholic Theology in the Nineteenth Century. The Quest for a Unitary Method. New York 1977.
3 Richard Griffiths, Révolution à rebours: le renouveau catholique dans la littérature en France de 1870 à 1914. Parijs 1971. Over deze beweging ook Doering, Jacques Maritain; Philippe Chenaux, Entre Maurras et Maritain. Une génération intellectuelle catholique. Parijs 1999; V. Chavagnac, “Les écrivains catholiques et l'esprit des années 20.' Pierre Colin (red.), Intellectuels chrétiens et esprit des années 20. Parijs 1997, 31-49. 4 De laatste jaren groeit evenwel de belangstelling voor de katholieke cultuurbewegingen in Frankrijk, getuige de in noot 3 genoemde studies van Colin (1997) en Chenaux (1999), het in noot 5 genoemde boek van Gugelot (1998) en de zeer recente studie van Hervé Serry, Naissance de l'intellectuel catholique. Parijs 2004. 5 Een studie over groepsvormingen onder Franse katholieke intellectuelen in termen 
van invloeden en verwantschappen en met veronachtzaming van institutionele structuren is Frédéric Gugelot, La conversion des intellectuels au catholicisme en France 1885-1935. Paris 1998. In zijn rijke overzichtswerk schenkt Gugelot geen aandacht aan Le Roseau d'or en de Chroniques.

6 Jacques Maritain, Saint Thomas d'Aquin, apôtre des temps modemes. Parijs 1923.

7 Jacques Maritain, Antimoderme. Parijs 1922, 21.

8 Jacques Maritain, Trois réformateurs: Luther, Descartes, Rousseau. Parijs 1925.

9 Zie Maaike Koffeman, Entre Classicisme et Modernité. La Nouvelle Revue Française dans le champ littéraire de la Belle Époque. Amsterdam 2003, 27 en 155-157 en W. Bronzwaer, 'Igor Stravinsky and T.S. Eliot: A Comparison of their Modernist poetics.' E.S. Schaffer (red.), Comparative Criticism. A Yearbook IV. Cambridge 1982, 169-191.

10 Over de bekeringsgolf onder Franse schrijvers en intellectuelen in de periode 1885-1935, zie Gugelot, La conversion des intellectuels.

I I Chenaux, Entre Maurraset Maritain.

12 Brief van Maritain aan Massis, 8 juli 1924, geciteerd naar Cheneaux, 58.

${ }_{13}$ Chenaux, 6o. Over Cocteau en Maritain ook Hubert \& Floucat, Jacques Maritain en $\mathrm{H}$. Gidel, Jean Cocteau. Parijs 1998.

14 Jean Cocteau, Lettre à Jacques Maritain. Paris 1926; Jacques Maritain, Réponse à Jean Cocteau. Paris 1926.
15 Zic Koffeman, Entre Classicisme et Modernité. 16 Chenaux, 56-60. Over de complexe verhouding tussen Gide en medewerkers van de NRF die zich bekeerden tot het katholicisme, zie Gugelot, 99-1 10

17 Chenaux, 66. Zie ook de gepubliceerde dagbocken van Maritain: Jacques Maritain, Carmets de notes. Parijs 1965. 18 Zie Chenaux, 66-68 en Koffeman, 102-107. 19 Zie de gepubliceerde dagboeken van Jacques en Raïssa Maritain: Jacques Maritain, Cahier de notes en Raïssa Maritain, Journal de Raissa, publiée par Jacques Maritain. Parijs z.j. [1963]. 20 Brief van Fumet aan Maritain, 22 oktober 1924, geciteerd naar Chenaux, 68.

21 Chenaux, 68-78.

22 Zie ook Chavagnac, 'Les écrivains catholiques'.

${ }_{23}$ Zie ook Dunaway, Jacques Maritain en Smith, Jacques Maritain.

24 'Le Roseau d'or', in: Chroniques, nr. 1, 1925, I-V. De tekst wordt door Chenaux toegeschreven aan Maritain. ${ }_{25}$ Over het classicisme - tomantiek-debat in Frankrijk tussen de twee wereldoorlogen schrijven ook Chenaux, Entre Maurras et Maritain en Chavagnac, 'Ies écrivains catholiques'. 26 Chenaux, 72 .

27 Medewerkerslijst in Chroniques, nr. 9, 1930. 28 Zie Dunaway, Jacques Maritain. Over het spanningsveld van nationalisme en internationalisme in de Franse katholieke cultuurbeweging, zie Chavagnac, 'Les écrivains catholiques'. 
29 Zie S. Levie, Commerce 1924-1932, een internationaal modemistisch tijdschrift. Amsterdam 1988, 76-91.

30 Zie de index.

31 Vergelijk Levie, 79.

32 Zie ook Béatrice Mousli, Valery Larbaud.

Parijs 1998 en Levie, 91 voor een evaluatie van Larbauds redactionele activiteiten.

33 Levie, Commerce.

34 Zie de index.

35 P. Ackroyd, T.S. Eliot. London 1984, 155.

Ook J. Harding, The Criterion. Cultural Politics and Periodical Networks in Inter-war Britain.

Oxford 2002, wijst op de invloed van de 'neoThomist literary revival in France' op Eliot. 36 Levie, 'T.S. Eliot en het continent. De rol van de Franse tijdschriften in de jaren twintig.' W. Bronzwaer (red.), T.S. Eliot. Een Amerikaan in Europa. Baarn 1988, 70-87.

37 Zie index en de bibliografische beschrijving in D. Gallup, T.S. Eliot. A Bibliography.

London 1969. Vanaf 1922 verscheen werk van Eliot in diverse Franse tijdschriften, waaronder Les Écrits Nouveaux, de NRF, Commerce, Le Navire d'Argent en Esprit. Over Eliots betrokkenheid bij de Franse tijdschriften, in het bijzonder de NRF en Commerce, zie Levie, 'T.S. Eliot en het continent' en Levie, Commerce, $153-162$.

38 Jacques Maritain, 'Poetry and religion.' The New Criterion, vol. V, nr. I (January 1927), 7-22 en nr. 2 (May 1927), 214-230.

39 T.S. Eliot, 'Notes.' The Criterion, vol. I (July 1923), 421.
40 T.S. Eliot, 'The Idea of a Literary Review.' In: The Criterion, vol. IV, nr. 1 (january 1926). 41 Over de internationale reikwijdte van de reeks zijn mij geen gegevens bekend. In de nogal Frans georiënteerde Nederlandse katholieke tijdschriften De Nieuwe Eeuw, Roeping en De Gemeenschap werd met een zekere regelmat aan de uitgaven binnen de reeks gerefereerd (zie ook noot 42).

42 Zie bijvoorbeeld Pieter van der Meer de Walcheren, 'De school van Le Roseau d'or.'

Roeping,jrg. 5, 1926-1927, 322-330.

43 R. Fernandez, 'L'intelligence et M. Maritain.' La Nouvelle Revue Française, juni 1925, 988. 44 Correspondance entre Jacques Rivière et Paul Claudel (1907-1914). Parijs 1925. Zie ook Chenaux, 73-74.

45 Gugelot, 307-312. 46 Idem, 309. 47 Gugelot. Aan de Chroniques wordt zijdelings gerefereerd op p. 454 48 Ik dank Sophie Levie en Maaike Koffeman voor hun kritische lezing van een eerste versie van dit artikel en Sjoerd van Faassen voor enkele literatuurverwijzingen. 49 Op het titelblad: 'La première journée de le Soulier de Satin ou le Pire n'est pas toujours sûr. Action Espagnole en IV Joumées. Au peintre José-Maria Sert. Copyright 1925 by Gallimard.' 50 Recks van 21 korte prozagedichten: 'Cristal', 'Au point du Nord', 'L'Ame et le Corps superposés', 'Regard Humain', 'Remords', 'Porte du vide', 'Faux portrait', 'Dehors', 'Le froid de l'air sur l'esprit et sur le visage', 
'L'Ame en péril', 'Réveil intérieur', 'Droit au corps', 'Rides de Givre', 'Mélange d'ombres', 'Et s'en Aller', 'Recueil de temps', 'Triangle', 'Première table', 'Derrière le clocher', 'L'eau du jour', 'Vitesse des mots'.

51 Vertaling door Maximilien Vox van twee essays uit Bellocs bundel Europe and the Faith: 'I. Le catholique et l'Europe.', 'Il. L'Europe et la Foie'. 'Notes du traducteur' op pp.

315-316.

52 Redactionele voetnoot op p. 1: 'Nous sommes heureux de publier cette importante étude, écrite en 1910, de l'auteur du Mystère de l'Eglise et de L'Esprit de saint Dominique, Le Père Humbert Clérissac est mort le 15 novembre 1914.'

53 Vertaling door Maurice Sachs van het verhaal The Young Visitors. 'Introduction' van de vertaler op pp. 131-132.

54 Opdracht 'A Jean Cocteau'. 55 Opdracht 'A Jean Aurenche.'

56 Opdracht 'A mes amis Jean Hô et Robert Kouan.'

57 Noot op p. 1: 'Ces pages doivent paraître comme supplément à la nouvelle édition d'Art et Scolastique, que publiera bientôt la librairie Rouart et fils.'

58 Redactionele voetnoot op p. 79: 'Cette traduction a été faite par Francis Jammes pour la collection Caritas (Bibliothèque de spiritualité franciscaine, Bloud et Gay éditeurs). Nous devons à l'obligeance du Père Martial Lekeux, directeur de cette collection, de pouvoir en donner la primeur.'
59 Redactionele voetnoot op p. 81: 'Ces notes ont été écrites en captivité par Jacques Rivière, comme toutes celles qui forment la première partic de $A$ la trace de Dicu, pour servir de charpente à un petit groupe de camarades.'

60 Vertaald door Jean de Menasce.

61 Opdracht: 'A Abraham-Beer Duff, Juif du galouth moldave.'

62 Opdracht: 'A mon ami Jacques Maritain.' $\sigma_{3}$ Vertaling van B. de Schloezer en J.E.

Pouterman.

64 Opdracht: 'A mon ami René Artur.' 65 Redactionele voetnoot op p. 314: 'Traduit de l'espagnol par Mme Mercédès Legrand et M. Valery Larbaud.'

66 Redactionele voetnoot op p. 64: 'Traduit de l'anglais par Jeanne Fournier-Pargoire.' 67 Redactionele voetnoot op p. 85: 'Copyright by Librairie Gallimard, 1928.' 68 Opdracht: 'Pour Georges Cattaui.' 69 Visioenen en gedichten van Marie des Vallées, ingeleid en vertaald door Emile Dermenghem. 7o Opdracht: 'A Roland Manuel et Nicolas Nabokoff.'

71 Voetnoot op p. 72 : 'Traduit de l'espagnol par Valery Larbaud.'

72 Redactionele voctnoot op p. 73 : 'Le Retour est la dernière partie du toman de Marcel Arland, intitulé l'Ordre, qui doit paraitre aux Éditions de la N.R.F. Nous en donnons ici le dénouement.'

73 Redactionele voetnoot op p. 3 10: "Traduit 
du russe par S.W. Kovalevsky.'

74 Redactionele voetnoot op p. 71 : 'Traduit de l'anglais par Jean Menasce.'

75 Redactionele voetnoot op p. 73: 'Charles Du Bos vient publier aux Éditions de la

Pléiade (J. Schiffrin) des Extraits d'un journal

(1908-1928), qui constituent pour l'histoire spirituelle de ce temps un témoignage

particulièrement précieux. Les extraits qu'il a bien voulu nous donner aujourd'hui pour les Chroniques du Roseau d'Or sont inédits.' 76 Redactionele voetnoot op p. 180: 'Traduit de l'anglais par Marthe Nouguier.'

77 Redactionele voetnoot op p. 360: 'Traduit du danois par Mme Benoit Léon Dufour.' 78 Redactionele voetnoot op p. 3: 'Traduit par Jean Chuzeville.'

79 Redactionele voetnoot op p. 5: 'Ces pages composent la préface de la nouvelle édition de notre ouvrage la Philosophie bergsonienne, études critiques (Paris, Rivière, 1914), actuellement

sous presse.

80 Reeks aforismen.

81 Reeks aforismen.

82 Redactionele voetnoot op p. 364: 'Traduit par Mlle J. Brunie.'

83 Redactionele voetnoot op p. 83: 'Copyright by J.O. Fourcade.' Op p. 128: 'Traduit du russe par Jean Chuzeville.'

84 Redactionele voetnoot op p. 132: 'Traduit de l'anglais par l'auteur.'

85 Voetnoot op p. 133: 'Fragment d'un livre à paraitre aux éditions du "Triangle" sous le titre: Marc Chagall et la peinture contemporaine (ill.).'

86 Volledige titel: 'Il y eut deux enfants de roi. Petit drame aquatique et lunaire en deux parties. D'après une chanson flamande.' Opdracht: 'A Madame Gérard d'Houville.' 